\title{
Similitude relationships for physical modelling of monopile-supported offshore wind turbines
}

\section{Subhamoy Bhattacharya}

University Senior Lecturer in Dynamics, University of Bristol, UK

Domenico Lombardi

Research Student, University of Bristol, UK

\author{
David Muir Wood \\ Emeritus Professor, University of Bristol, UK
}

Offshore wind turbines are considered as an important element of the future energy infrastructure. There is currently a surge in the construction of such facilities in Europe, yet there is no track record of long-term performance of these structures. Offshore wind turbines are dynamically sensitive structures because of the very nature of the structural form (tall and slender) and the different types of dynamic and cyclic loading imposed on them. Lack of data concerning long-term performance indicates a need for detailed investigation to predict the future performance of such structures. Arguably this can be best carried out through small-scale well-controlled laboratory experimental investigation. In this paper, scaling laws are derived for the design of such model tests for studying the long-term performance. Non-dimensional groups that need to be preserved are identified while carrying out these tests. The effectiveness of these chosen non-dimensional groups is investigated by carrying out controlled tests on a 1:100 scale offshore wind turbine. Typical experimental data are presented.

\section{Notation}

CSR

$D$

E

$e_{\mathrm{p}}$

$e_{\mathrm{s}}$

$f_{\mathrm{f}}$

$f_{\mathrm{n}}$

$G$

$K_{\mathrm{L}}$

$K_{\mathrm{R}}$

$K_{\mathrm{V}}$

$k_{\mathrm{h}}$

M

$N$

$P$

$t$ cyclic stress ratio

pile diameter

pile Young's modulus

strain in pile wall thickness

average strain in soil

forcing frequency

natural frequency

soil shear modulus

stiffness of transverse spring

stiffness of rotational spring

stiffness of vertical spring

horizontal coefficient of soil permeability

external moment acting at the pile head

number of cycles of loading

horizontal load

time

pile wall thickness

distance between foundation level and application of $P$

linear shear strain threshold

pile head lateral deflection

damping ratio

effective vertical stress on the soil at the same depth as above

pile yield stress $\tau_{\text {cyc }}$

cyclic shear stress imposed by the pile on the soil at a particular depth

\section{Introduction}

\subsection{Loading on offshore wind turbines}

Offshore wind turbines are dynamically sensitive structures that are placed in adverse environmental conditions (with strong wind and wave loading of a cyclic nature). This makes the design of foundations extremely challenging. Figure 1(a) shows a photograph of a monopile-supported wind turbine and Figure 1(b) schematically shows the typical wind and wave pressure distribution along the length of the tower and the foundation. The tower, above the water, experiences two types of loads:

(a) the bottom part of the tower, unobstructed by the spinning turbine blade, experiences a nearly constant value of the wind loading

(b) the top part of the tower, which is periodically obstructed by the spinning of the blades, is subjected to a cyclic loading often called the blade passing effect $(2 \mathrm{P} / 3 \mathrm{P})$ or blade shadowing effect or wind shielding effect in the literature. 
International Journal of Physical Modelling in Geotechnics Volume 11 Issue 2
Similitude relationships for physical modelling of monopilesupported offshore wind turbines

Bhattacharya, Lombardi and Muir Wood

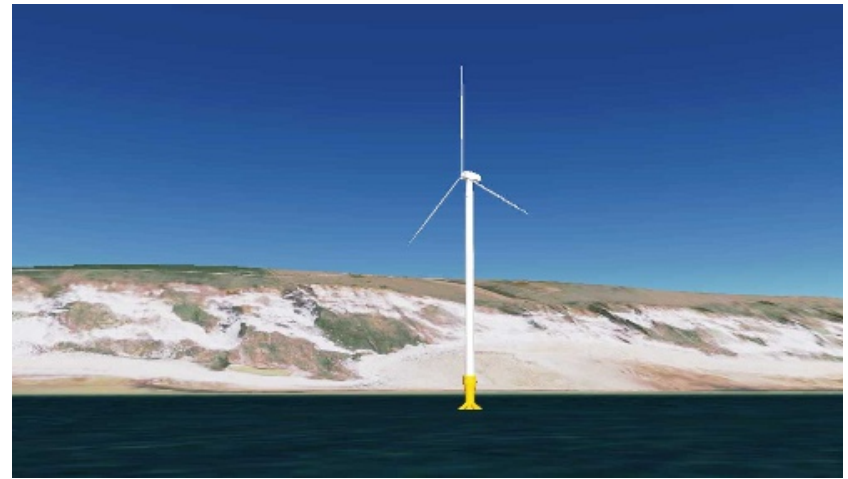

(a)

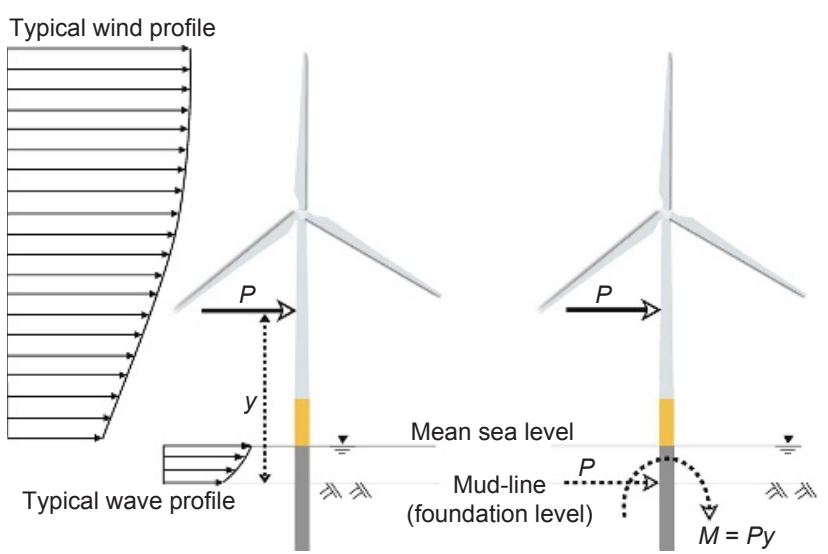

(b)

Figure 1 (a). Typical offshore wind turbine (Cox and Jones, 2010); (b). Schematic representation of the environmental load acting on offshore wind turbine supported on a monopile; (c) equivalent force model showing a force and a moment at the foundation level

The total environmental lateral load acting on the offshore wind turbine in Figure 1(b) can be modelled simplistically as an instantaneous static horizontal load, $P$, acting at a distance $y$ above the foundation level. Thus $P$ represents the resultant lateral load on the tower that must be resisted by the monopile foundation. Figure 1(b) shows an equivalent force model for the foundation where the lateral load $(P)$ on the tower is replaced by a force $(P)$ and a moment $(M)$ at the pile head.

Figure 2 shows a structural model of a wind turbine currently being used in practice (see for example the software GH Bladed or Samtech) to predict the natural frequency of the system. The lateral vibration of wind turbines is controlled by two foundation springs: $K_{\mathrm{L}}$ (transverse spring) and $K_{\mathrm{R}}$ (rotational spring). The dynamic response of these structures is dependent on the support condition (i.e. the stiffness of the foundation in Figure 2), which relies on the strength and stiffness of the surrounding soil. Under moderate to high cyclic loading most soils change their properties, which may alter the stiffness of

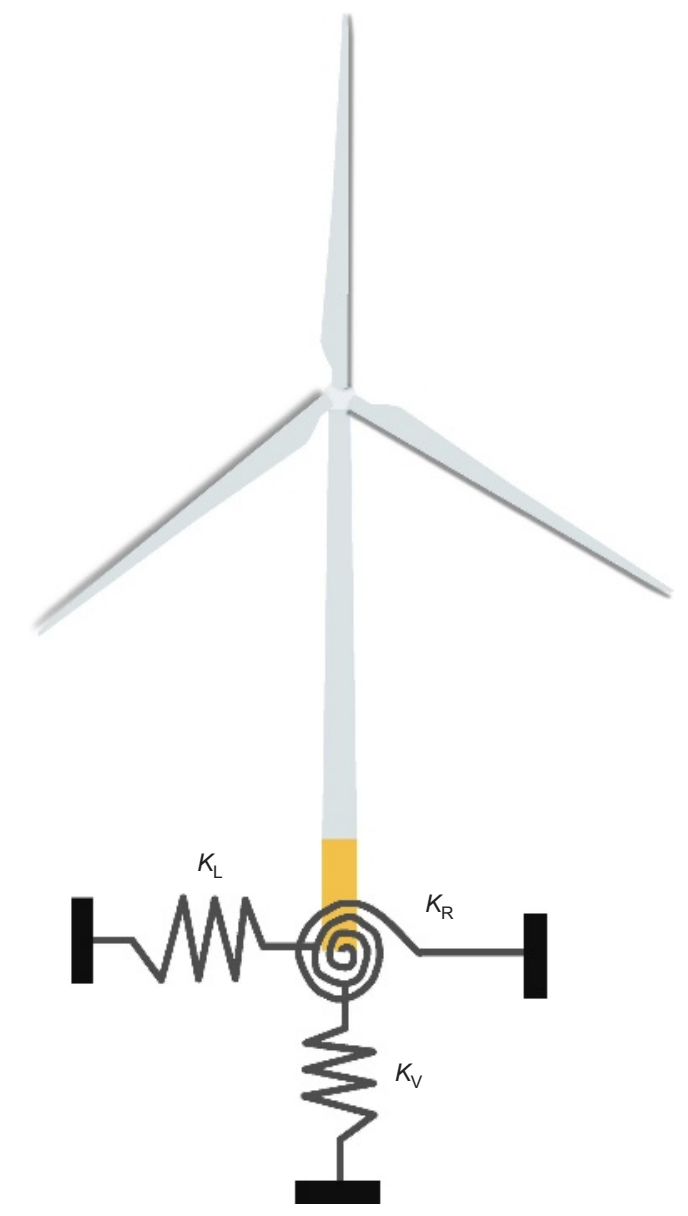

Figure 2. Simplified structural model

the foundation and this may have an adverse effect on the long-term performance. Therefore, the dynamic behaviour and the prediction of the long-term performance of offshore wind turbines require a deeper understanding of various dynamic interactions between the superstructure, foundation, soil and external loads.

\subsection{Frequency of the loading on wind turbine foundations:}

Figure 3 shows the main frequencies for a three-bladed $3 \mathrm{MW}$ Vestas V90 wind turbine with an operational interval of 8.6 to 18.4 revolutions/min: the rotor frequency (often termed as $1 \mathrm{P}$ ) lies in the range $0 \cdot 14-0 \cdot 3 \mathrm{~Hz}$ and the corresponding 'blade passing frequency' for a three-bladed turbine lies in the range $0 \cdot 42-0.9 \mathrm{~Hz}$. The figure also shows a typical frequency distribution for wind and wave loading. The peak frequency of offshore waves is about $0 \cdot 1 \mathrm{~Hz}$. It is clear from the frequency content of the applied loads that the designer of the turbine and foundation has to select a system frequency (the global frequency of the overall wind turbine-foundation system) which lies outside 


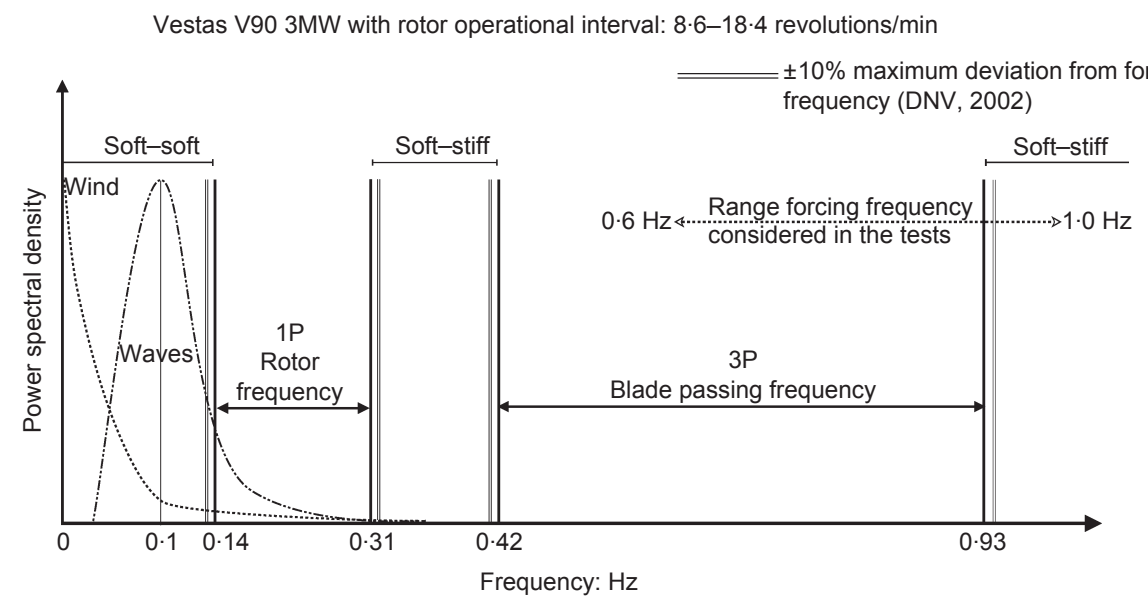

Figure 3. Main forcing frequencies acting on a Vestas V90 $3 \mathrm{MW}$

offshore wind turbine

these in order to avoid system resonances. The usual choice would lie between turbine and blade passing frequencies (so-called 'soft-stiff', option 2 in Figure 3). There are two challenges

(a) the foundation stiffness must be estimated very accurately from the available soil data

(b) the potential for change in foundation stiffness with time as a result of the cyclic loading must be understood so that the risks of the system frequency coinciding with a loading frequency can be avoided.

\subsection{Purpose and scope of the paper}

Offshore wind turbines are relatively new structures and there is no track record of long-term performance (say 20 to 30 years). Under these circumstances, experimental investigations on physical wind turbine models can provide valuable information for understanding the dynamic behaviour and long-term performance of these relatively new structures. The design and interpretation of any test carried out on a smallscale model require the assessment of a set of laws of similitude that relate the model to the prototype structure. The paper therefore has the following aims:

(a) to derive the scaling laws necessary to study dynamic soilstructure interaction and also to identify appropriate controlling dimensionless groups

(b) to present typical test results from a study in which a 1:100 scale wind turbine model was tested in the Bristol Laboratory for Advanced Dynamics Engineering (BLADE) and then to comment on the usefulness of the dimensionless groups derived in this paper.
It must be mentioned that there are three design limit states that may govern the design of offshore wind turbines foundations:

(a) ultimate limit state, that is failure of the foundations

(b) serviceability limit state, that is the deformations or the tilting of the wind turbine tower or the foundation is more than acceptable

(c) fatigue limit state, that is the material is subjected to large number of cycles which may be close to its fatigue life.

The focus of the paper is not on the ultimate limit state but on serviceability limit state.

\subsection{A brief summary of the available literature in the public domain}

Long-term performance of wind turbines is currently a topic of research as monitoring of limited installed monopile offshore wind turbines has indicated a gradual degradation of the overall system structural dynamics from design requirements; see for example the data from Lely wind farm reported by Zaaijer (2006) and Kuhn (2002). Research on pile-soil interactions without the effects of superstructure has recently been carried out by Li et al. (2010) and Leblanc et al. (2010). Research on the effects of large numbers of cycles of loading on a soil sample has been investigated by Wichtmann (2007). An analytical solution for estimating the first natural frequency of the system taking soil-structure interaction into account has been carried out by Adhikari and Bhattacharya $(2010,2011)$. In contrast to these reported researches, the work presented in this paper is unique in considering the dynamics of the overall system. 
International Journal of Physical Modelling in Geotechnics Volume 11 Issue 2
Similitude relationships for physical modelling of monopilesupported offshore wind turbines

Bhattacharya, Lombardi and Muir Wood

\section{Scaling and modelling}

Derivation of the correct scaling laws constitutes the first step in an experimental study. These are necessary to interpret the model test results in order to scale up the results for prediction of prototype consequences. Every physical process can be expressed in terms of non-dimensional groups and the fundamental aspects of physics must be preserved in the design of model tests. The necessary steps associated with designing such a model, to be implemented either in one- $\boldsymbol{g}$ or a multi- $\boldsymbol{g}$ testing environment, can be stated as follows:

(a) to deduce the relevant non-dimensional groups by thinking of the mechanisms that govern the particular behaviour of interest both at model and prototype scale

(b) to ensure that a set of crucial scaling laws are simultaneously conserved between model and prototype through pertinent similitude relationships

(c) to identify scaling laws which are approximately satisfied, and those which are violated and which therefore require special consideration.

Examples of derivation of scaling laws for general dynamic problems can be found in the literature, see for example Iai (1989) and Muir Wood et al. (2002).

\subsection{Identifying non-dimensional groups}

Offshore wind turbines are dynamically sensitive structures because of the multiple frequencies which contribute to the complexity of the interaction of the foundation with the supporting soil. The study of the dynamics as well as the assessment of the long-term performance of offshore wind turbines involves the following issues.

(a) Vibration of the pile owing to the environmental loads will induce cyclic strains in the soil in the vicinity of the pile. In order to study the changes in soil stiffness owing to these cyclic strains, the developing soil strain around the field must be monitored. These soils are saturated and therefore pore pressures are likely to develop as a result of these cyclic strains. The pore pressure developed may dissipate to the surrounding soil, depending on the frequency of the loading.

(b) Changes in the soil stiffness owing to the cyclic loading may lead to changes in foundation stiffness $\left(K_{\mathrm{L}}, K_{\mathrm{R}}\right.$ in Figure 2), which in turn will alter the natural frequency of the system. Therefore the relationship between the foundation characteristics and the overall system dynamics, in other words, the soil-structure interaction, is important for overall system performance.

(c) Repeated cyclic stresses will be generated in the pile owing to cyclic loading. Therefore foundation fatigue is also a design issue.
Based on the above discussion, the following physical mechanisms are considered important in order to develop the non-dimensional groups.

(a) the strain field in the soil around a laterally loaded pile which will control the degradation of soil stiffness

(b) the cyclic stress ratio in the soil in the shear zone

(c) the rate of soil loading which will influence the dissipation of pore water pressure

(d) the system dynamics, the relative spacing of the system frequency and the loading frequency

(e) bending strain in the monopile foundation for considering the non-linearity in the material of the pile

(f) fatigue in the monopile foundation.

\subsection{Strain field in the soil around the laterally loaded pile}

Repeated shear strain may reduce the stiffness of saturated soils. Assuming that the changes in soil stiffness drive the long-term performance, the average strain next to a pile is a governing criterion and must be preserved in order to ensure similar stiffness degradation in both model and prototype. The relevant nondimensional group can be derived by considering that the average shear strain field around a laterally moving pile can be expressed as a function of pile head deflection $(\delta)$ and pile outer diameter $(D)$

1. $\varepsilon_{\mathrm{s}} \propto \frac{\delta}{D}$

Klar (2008) suggested a value of $2 \cdot 6$ for the coefficient of proportionality between the average strain in the soil and the ratio of head deflection and pile diameter. However, there is a lack of consensus in the literature on this proportionality coefficient. The pile head deflection is a function of the external load, $P$, the shear modulus of the soil, $G$, and the pile diameter, $D$. Therefore, the average strain field in the soil around a pile can be expressed as a function of only three parameters

2. $\varepsilon_{\mathrm{s}}=f(P, D, G)$

The parameters in Equation 2 can be used to obtain a dimensionless group as follows

3. $\varepsilon_{\mathrm{s}}=f\left(\frac{P}{G D^{2}}\right) \quad \frac{[F]}{\left[F L^{-2}\right][L]^{2}}$

Equation 3 describes the non-dimensional group that takes into account the strain field in the soil generated by a lateral loaded pile. Equation 3 shows that the strain in the soil is directly proportional to the horizontal load applied at the pile 
Similitude relationships for

physical modelling of monopile-

supported offshore wind

turbines

Bhattacharya, Lombardi and Muir

Wood head, inversely proportional to the soil stiffness and inversely proportional to the square of the pile diameter.

\subsection{Cyclic stress ratio (CSR) in the soil in the shear zone}

In geotechnical earthquake engineering, it is well established that degradation of a soil owing to liquefaction-type failure is a function of cyclic stress ratio (CSR), which is defined as the ratio of the shear stress to the effective vertical stress at a particular depth, defined by Equation 4, (see, for example, Seed and Idriss (1971)). The CSR can be expressed by Equation 4

4. $\mathrm{CSR}=\frac{\tau_{\mathrm{cyc}}}{\sigma_{\mathrm{v}}^{\prime}}$

5. $\tau_{\mathrm{cyc}} \propto \frac{P}{D^{2}} \quad \frac{[F]}{[L]^{2}}$

where

$\tau_{\text {cyc }}=$ cyclic shear stress imposed by the pile on the soil at a particular depth

$\sigma_{\mathrm{v}}^{\prime}=$ effective vertical stress on the soil at the same depth

The vertical effective stress can be related to the shear modulus $(G)$ of the soil

6. $\sigma_{v}^{\prime} \propto G \frac{[F]}{[L]^{2}}$

It is usually found that $G$ is proportional to $\sigma_{\mathrm{v}}{ }^{n}$ where the value of $n$ depends on the type of soil. The value of $n$ varies between 0.435 to 0.765 for sandy soil (Wroth et al., 1979) but a value of 0.5 is commonly used. For clayey soil, the value of $n$ is generally taken as 1 .

Combining Equations 4-6, one can see that the non-dimensional group expressed by Equation 3 can also guarantee similarity of cyclic stress ratio. This leads us to a nondimensional group (Equation 7) that must be satisfied

7. $\left(\frac{P}{G D^{2}}\right)_{\text {model }}=\left(\frac{P}{G D^{2}}\right)_{\text {prototype }}$

It is interesting to note that using two different approaches based on average strain in the soil and on the CSR dimensional analysis leads to a unique non-dimensional group given by Equation 7.

\subsection{Rate of soil loading}

Pore pressure generation and subsequent dissipation is a function of the frequency of loading exerted on soil. The time, $t$, in which the pore pressure dissipates will be directly proportional to the soil permeability, $k_{\mathrm{h}}$, and inversely proportional to characteristic length, for example monopile diameter, $D$ )

8. $t \propto \frac{k_{\mathrm{h}}}{D}$

Considering the variables in Equation 8, one can obtain the only possible dimensionless group

9. $\left(\frac{k_{\mathrm{h}} t}{D}\right) \infty \frac{\left[L T^{-1}\right][T]}{[L]}$

Replacing time $(t)$ by forcing frequency $\left(f_{\mathrm{f}}\right)$, the pore pressure dissipation is therefore correctly modelled when

10. $\left(\frac{k_{\mathrm{h}}}{f_{\mathrm{f}} D}\right)_{\text {model }}=\left(\frac{k_{\mathrm{h}}}{f_{\mathrm{f}} D}\right)_{\text {prototype }}$

\subsection{System dynamics}

In order correctly to simulate the system dynamics resulting from the interaction between the external loads (i.e. forcing frequency) and the wind turbine (i.e. natural frequency), the ratio between the forcing frequency and the natural frequency of the turbine should be of the same order in the physical model and prototype. The main forcing frequencies are outlined below (see also Figure 3).

(a) Environmental loading: the predominant wave and wind forcing frequency is typically around $0 \cdot 1 \mathrm{~Hz}$.

(b) Rotor frequency: it represents the frequency of the blade rotation, and is generally indicated by $1 \mathrm{P}$. As shown in Figure 3, typical values are in the range $0 \cdot 14-0 \cdot 3 \mathrm{~Hz}$.

(c) Wind shielding effects of the blade on the tower: when the blade passes the tower the shadowing effect of the wind load causes a cyclic load on the tower. This frequency is indicated by $3 \mathrm{P}$ (or 2P for a two-bladed rotor). Evidently the blade passing frequency is the product of the rotor frequency and the number of blades.

It is considered useful to review the relevant codes of practice. DNV guidelines (2002) suggest that the natural frequency of the wind turbine should not come close to the forcing frequency arising from the imposed environmental loads. The guidelines also specify that the global frequency of the system should be at least $\pm 10 \%$ away from the $1 \mathrm{P}$ and $2 \mathrm{P} / 3 \mathrm{P}$ frequencies indicated by dotted lines in Figure 3. Depending on the value of the 
International Journal of Physical Modelling in Geotechnics Volume 11 Issue 2
Similitude relationships for physical modelling of monopilesupported offshore wind turbines

Bhattacharya, Lombardi and Muir Wood natural frequency of the wind turbine in relation to the loading frequencies, three different design regimes are possible: softsoft, soft-stiff and stiff-stiff (as indicated in Figure 3). From Figure 3 it may be noted that for any of these three design approaches, the ratio between the forcing and the natural frequency is in fact close to 1 . This aspect must be preserved also in the physical model. Therefore the non-dimensional groups for the correct modelling of the dynamics of the system can be expressed as a ratio between the forcing and natural frequency

11. $\left(\frac{f_{\mathrm{f}}}{f_{\mathrm{n}}}\right)_{\text {model }}=\left(\frac{f_{\mathrm{f}}}{f_{\mathrm{n}}}\right)_{\text {prototype }}$

\subsection{Bending strain in the monopile}

The strain in the monopile is a function of its mechanical properties and the characteristics of the external loads. As shown in Figure 1(b), the external loads owing to the wind and the waves can be conveniently modelled as a horizontal force $(P)$ acting at the distance $y$ above the foundation level. Making the assumption that the monopiles remain elastic, the strain in the pile wall will be a function given by Equation 12

12. $\varepsilon_{\mathrm{p}}=f\left(P, y, D, E, t_{\mathrm{w}}\right)$

where

$t_{\mathrm{w}}$ is the pile wall thickness

$E$ is Young's modulus of the pile

The parameters in Equation 12 can be combined to obtain a dimensionless group

13. $\varepsilon_{\mathrm{p}}=f\left(\frac{P y}{E D^{2} t_{\mathrm{w}}}\right)$

$$
\frac{[F][L]}{\left.\left[F L^{-2}\right][L]^{2}\right][L]}
$$

In order to model the material non-linearity of the pile correctly, the non-dimensional group expressed by Equation 14 must be preserved in the model and the prototype

14. $\left(\frac{P y}{E D^{2} t_{\mathrm{w}}}\right)_{\text {model }}=\left(\frac{P y}{E D^{2} t_{\mathrm{w}}}\right)_{\text {prototype }}$

\subsection{Fatigue in the monopile}

The stress in the monopile can be an important parameter influencing the fatigue phenomena. Fatigue relates to the degradation of the material after a large number of load cycles $\left(>10^{7}\right.$ cycles). The design of an offshore wind turbine must ensure that the fatigue limit state (FLS) is satisfied (DNV, 2007).
The fatigue in the monopile can be expressed as a function of the external load $P$, pile diameter, $D$, pile wall thickness, $t_{\mathrm{w}}$, vertical distance $y$ between the application point of the load $P$ and the pile head, and the yield stress of the material, $\sigma_{\mathrm{y}}$

15. $f\left(P, D, t_{\mathrm{w}}, y, \sigma_{\mathrm{y}}\right)$

The parameters in Equation 15 can be combined to obtain a dimensionless group

16. $f\left(\frac{P y}{\sigma_{\mathrm{y}} D^{2} t_{\mathrm{w}}}\right) \frac{[F][L]}{\left.\left[F L^{-2}\right][L]^{2}\right][L]}$

Equation 16 represents the non-dimensional group required to take account of the fatigue phenomenon. This can be correctly modelled when Equation 17 is satisfied

17. $\left(\frac{P y}{\sigma_{\mathrm{y}} D^{2} t_{\mathrm{w}}}\right)_{\text {model }}=\left(\frac{P y}{\sigma_{\mathrm{y}} D^{2} t_{\mathrm{w}}}\right)_{\text {prototype }}$

The next section of the paper describes typical results of highquality small-scale experiments to explore the usefulness of these dimensionless groups.

\section{1-g tests on model offshore wind turbine}

Pilot experiments have been carried out at the University of Bristol in order to study the long-term performance of offshore wind turbines.

\subsection{Details of test set-up}

An experimental investigation has been carried out in the Bristol Laboratory for Advanced Dynamics Engineering (BLADE). Nineteen tests were carried out on a small-scale offshore wind turbine, with a Vestas V90 3MW turbine being taken as a notional prototype. The experimental arrangement is shown in Figure 4 and more details are given by Lombardi (2010). Table 1 shows the relevant parameters for the prototype and model wind turbines. The soil conditions at the Vestas installation in the Kentish Flat wind farm are considered as the $k_{\mathrm{h}}$ prototype. The soil at the site is layered with seabed sand underlain by soft to firm clay on top of the London Clay formation. The average soil shear modulus is taken to be in the order of $80 \mathrm{MPa}$. Based on the method developed by Adhikari and Bhattacharya (2010), Lombardi (2010) estimated the natural frequency of the entire system at the Kentish Flat location to be around $0.38 \mathrm{~Hz}$. A homogeneous soil profile of soft speswhite kaolin clay was prepared for the model tests. From bender element tests, the shear modulus was estimated to be $6 \mathrm{MPa}$. 
Similitude relationships for

physical modelling of monopile-

supported offshore wind

turbines

Bhattacharya, Lombardi and Muir

Wood

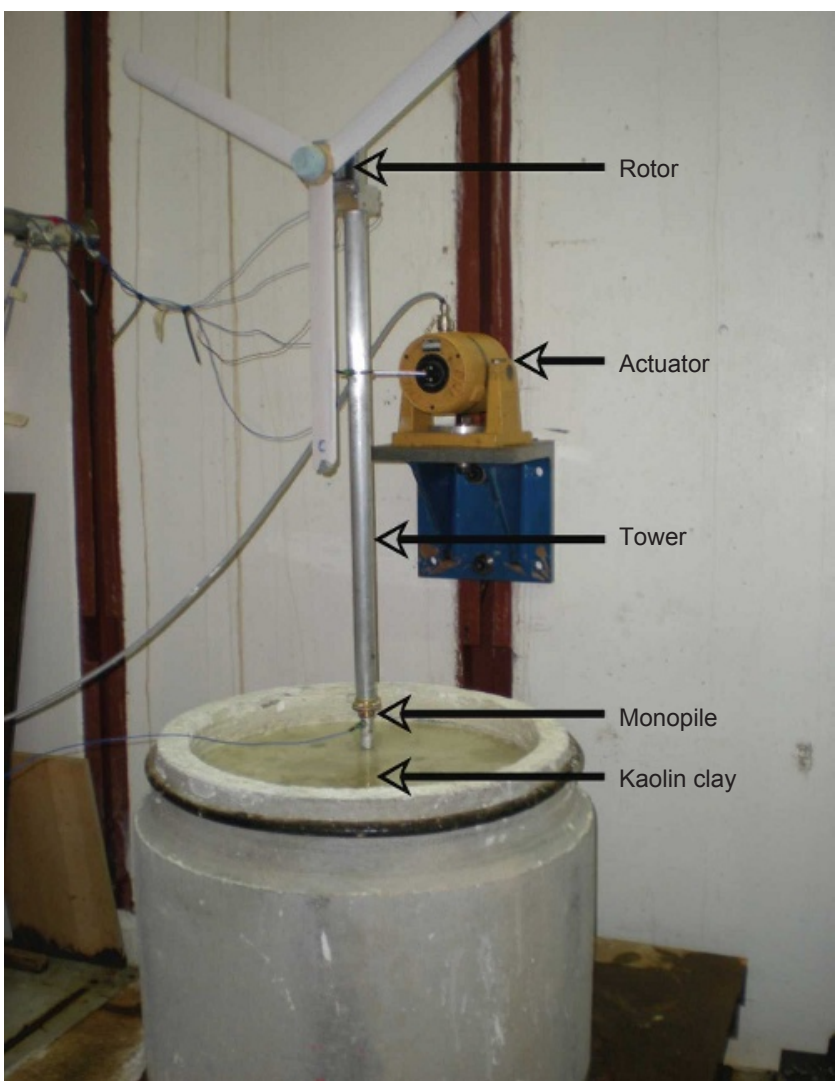

Figure 4. Physical model of a small-scale offshore wind turbine
Modelling of the environmental dynamic loads which act on a prototype offshore wind turbine was achieved using an electrodynamic actuator (Figure 4) fixed to the laboratory strong wall and connected to the model wind turbine tower. The force applied to the wind turbine could be constantly monitored by a force sensor. The blades were rotated by a DC electric motor to model the $1 \mathrm{P}$ loading and also to give some aerodynamic damping to the system. Precise measurement of displacements, velocities and accelerations was performed using LVDTs (linearly varying differential transformer) and piezoelectric accelerometers. Table 2 shows the non-dimensional groups for the model and a typical prototype (3MW Vestas V90), while the meaning of the symbols is illustrated in Figure 5.

The data recorded during the tests (i.e. acceleration response) were analysed in the frequency domain for the assessment of the natural frequency and damping of the model wind turbine after different numbers of cycles of loading.

\subsection{Experimental procedure}

A typical test consists of the application of the cyclic loading for a particular time interval (or certain number of cycles) and then measuring the frequency and damping of the system by a free vibration test. In the free vibration test (also known as a 'snap back' test in the literature), the actuator was disconnected from the tower and the tower was given a smallamplitude vibration and the acceleration of the system was recorded.

\begin{tabular}{lll}
\hline Parameter & Prototype turbine & Model turbine \\
\hline Lateral load $(P)$ & $1 \cdot 16 \mathrm{MN}$ & $2 \mathrm{~N}$ \\
& $($ Typical value $)$ & \\
Soil stiffness $(G)$ & $80 \mathrm{MPa}$ & $6 \mathrm{MPa}$ \\
Diameter of the pile $(D)$ & $4300 \mathrm{~mm}$ & $22 \mathrm{~mm}$ \\
Soil permeability $\left(k_{\mathrm{h}}\right)$ & $10^{-9} \mathrm{~m} / \mathrm{s}$ & $10^{-9} \mathrm{~m} / \mathrm{s}$ \\
Natural frequency $\left(f_{\mathrm{n}}\right)$ of the system & $0 \cdot 38 \mathrm{~Hz}$ & $2 \cdot 96 \mathrm{~Hz}$ \\
& Lombardi $(2010)$ & $(\mathrm{measured} \mathrm{in} \mathrm{the} \mathrm{lab)}$ \\
Forcing frequency $\left(f_{\mathrm{f}}\right) *$ & $0 \cdot 14-0 \cdot 3(1 \mathrm{P})$ & $0 \cdot 66(1 \mathrm{P})$ \\
& $0 \cdot 42-0 \cdot 9(3 \mathrm{P})$ & $2 \mathrm{~Hz}(3 \mathrm{P})$ \\
& & $20 \mathrm{~Hz}(3 \mathrm{P})$ \\
& & $125 \mathrm{~Hz}(3 \mathrm{P})$ \\
Distance of the lever arm of total lateral load $(P)$, i.e. $y$ & $40000 \mathrm{~mm}$ & $600 \mathrm{~mm}$ \\
Thickness of the pile wall $\left(t_{\mathrm{w}}\right)$ & $45 \mathrm{~mm}$ & $1 \cdot 3 \mathrm{~mm}$ \\
Young's modulus of the pile material $(E)$ & Steel & Dural alloy
\end{tabular}

*For model turbine, tests were carried out with three different forcing frequencies of $2 \mathrm{~Hz}, 20 \mathrm{~Hz}$ and $125 \mathrm{~Hz}$ applied by electrodynamic actuator. The $1 \mathrm{P}$ frequency of $0.66 \mathrm{~Hz}$ represents the rotational rotor speed was applied by an electric motor powered by a DC supply

Table 1. Values for the prototype turbine in Kentish Flat wind farm and model wind turbine 


\begin{tabular}{|c|c|c|c|}
\hline Physical mechanism & Non-dimensional group & Model & Prototype \\
\hline $\begin{array}{l}\text { Strain field in the soil and } \\
\text { cyclic stress ratio (CSR) }\end{array}$ & $\left(\frac{P}{G D^{2}}\right)$ & $6 \cdot 89 \times 10^{-4}$ & $7 \cdot 84 \times 10^{-4}$ \\
\hline Rate of loading* & $\left(\frac{k_{\mathrm{h}}}{f_{\mathrm{f}} D}\right)$ & $\begin{array}{l}2 \cdot 27 \times 10^{-8}\left(f_{f}=2 \mathrm{~Hz}\right) \\
2 \cdot 27 \times 10^{-9} \\
\left(f_{f}=20 \mathrm{~Hz}\right) \\
3 \cdot 64 \times 10^{-10} \\
\left(f_{f}=125 \mathrm{~Hz}\right)\end{array}$ & $\begin{array}{l}3 \cdot 88 \times 10^{-10} \\
\text { (Here the blade passing frequency of } \\
0 \cdot 6 \mathrm{~Hz} \text { corresponding to the } \\
\text { operational frequency of } \\
12 \text { revolutions/min is considered) }\end{array}$ \\
\hline System dynamics & $\left(\frac{f_{\mathrm{f}}}{f_{\mathrm{n}}}\right)$ & $0 \cdot 6-1 \cdot 0$ & $\begin{array}{l}0 \cdot 5 \text { (based on } 1 \mathrm{P}) \\
1 \cdot 6 \text { (based on } 3 \mathrm{P}) \\
\text { The range: } \\
0 \cdot 36 \text { to } 0 \cdot 78(1 \mathrm{P}) \\
1 \cdot 1 \text { to } 2 \cdot 36(3 \mathrm{P})\end{array}$ \\
\hline Strain in the monopile & $\left(\frac{P y}{E D^{2} t_{\mathrm{w}}}\right)$ & $2 \cdot 72 \times 10^{-5}$ & $2.66 \times 10^{-4}$ \\
\hline Stress in the monopile & $\left(\frac{P y}{\sigma_{\mathrm{y}} D^{2} t_{\mathrm{w}}}\right)$ & $7 \cdot 63 \times 10^{-3}$ & $0 \cdot 10$ \\
\hline
\end{tabular}

*The non-dimensional value related to rate of loading is assessed in the model for three different force frequencies $(2,20$ and $125 \mathrm{~Hz}$

Table 2. Values of the non-dimensional groups for both model and prototype

The cyclic lateral loading was applied at three different frequencies $(2 \mathrm{~Hz}, 20 \mathrm{~Hz}$ and $125 \mathrm{~Hz})$ and for different lateral load magnitudes. This set of tests created a database of change of frequency and damping of the wind turbine system for different values of

(a) strain field in the soil, that is various values of $\left(P / G D^{2}\right)$

(b) forcing frequency $\left(f_{\mathrm{f}}\right)$

(c) number of cycles of loading $(N)$.

The next section of the paper presents typical test results in order to illustrate the usefulness of the non-dimensional groups.

\subsection{Typical results and discussion}

Figure 6 shows the variation of the normalised frequency of the system with respect to the number of cycles of loading for various strain levels in the soil. As expected, higher strain levels lead to higher reduction in natural frequency of the model. It is interesting to note that for a low value of $\left(P / G D^{2}\right)$ there is practically no degradation in the natural frequency. Figure 7 shows the variation of secant stiffness with strain for fully saturated cohesive soil adapted from Vucetic (1994). It is clear from Figure 7 that there exists a strain level $\gamma_{\mathrm{tl}}$ for which there is no stiffness degradation. This reference shear strain is often termed as 'threshold linear (tl) shear strain'. The experimental results presented in Figure 6 indicate that the non-dimensional group $\left(P / G D^{2}\right)$ can be mapped to $\gamma_{\mathrm{tl}}$, which can be considered as a fundamental property of a soil that can be obtained from routine element tests. However, more study is necessary to prove or disprove the hypothesis. As soil stiffness decreases, the frequency ratio $\left(f_{\mathrm{f}} / f_{\mathrm{n}}\right)$ also changes during the test in the range $0 \cdot 6-0 \cdot 9$.

Figure 8 shows, as expected, the increase in damping of the model with the number of cycles. Higher damping variations are recorded for larger strain fields in the soil. Figure 9 shows that for a particular strain level, $P / G D^{2}=0 \cdot 34 \%$, the drop in frequency is higher if the forcing frequency is close to the natural frequency of the system. This is expected because of resonance type mechanisms. Figure 10 presents the corresponding damping values. Figure 11 shows the dynamic response for the entire set of tests.

The test results indicate that the non-dimensional groups identified can capture the stiffness degradation of the system. The test result justifies the current trend of large-diameter piles being used to support offshore wind turbines since average strain decreases with square of the diameter of the pile.

There are a few points that should be noted.

(a) It may be observed from Table 2 that, in order to maintain the similitude of rate of loading, that is satisfy Equation 10, the forcing frequency should be $125 \mathrm{~Hz}$. 
Similitude relationships for

physical modelling of monopile-

supported offshore wind

turbines

Bhattacharya, Lombardi and Muir

Wood

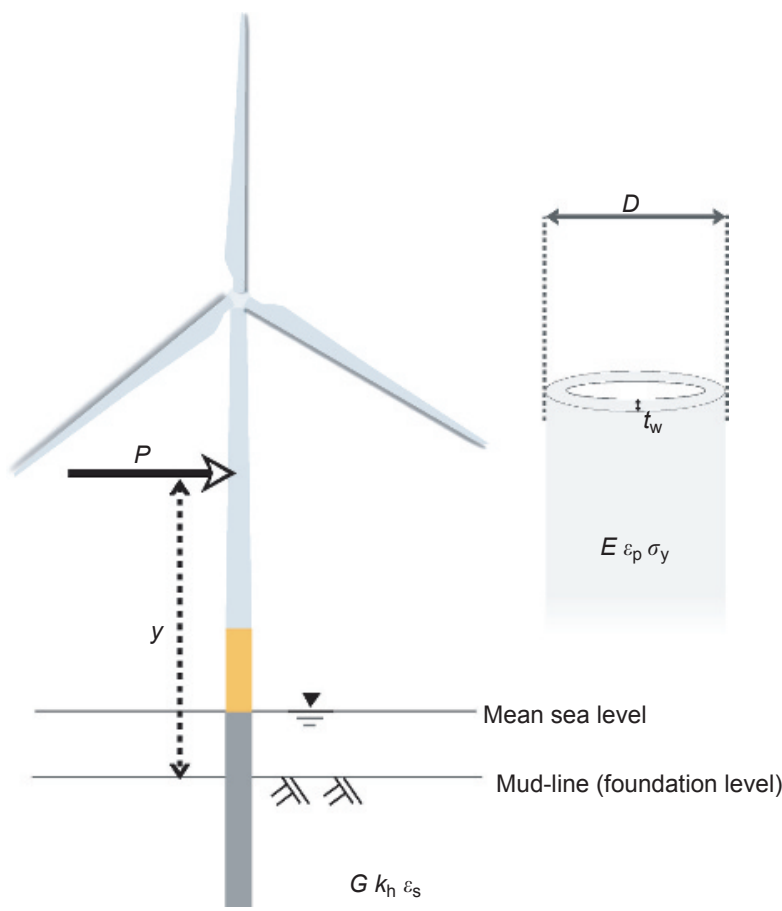

Figure 5. Schematic representation of the parameter that characterised the strain field around the pile

This would ensure that the group $\left(k_{\mathrm{h}} / f_{\mathrm{f}} D\right)$ is of the same order of magnitude for both the model and the prototype. However, this will not model the system dynamics correctly because the resulting ratio $f_{\mathrm{f}} / f_{\mathrm{n}}$ is about 42 . On the other hand, if a forcing frequency of $2 \mathrm{~Hz}$ is used to maintain the similitude of system dynamics, the dissipation of pore pressure is not modelled accurately as the $\left(k_{\mathrm{h}} / f_{\mathrm{f}} D\right)$ group is two orders of magnitudes less than the prototype. Therefore, if the system dynamics parameter is

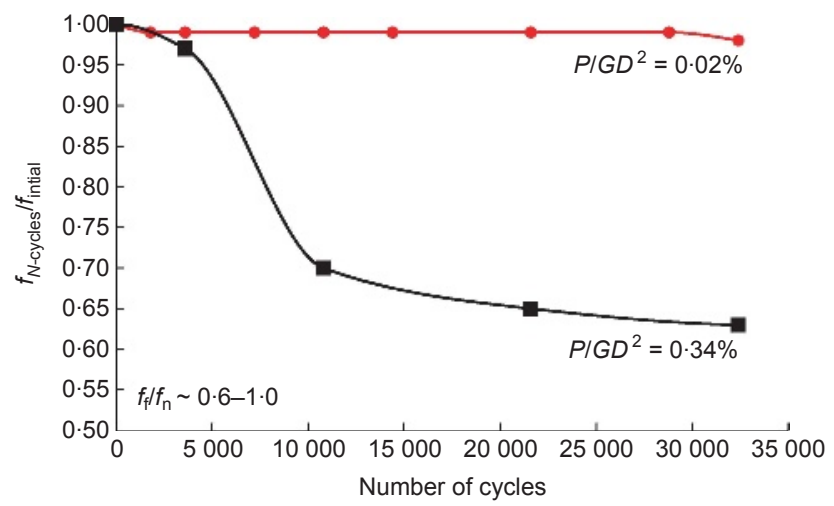

Figure 6. Change in frequency with the number of cycles for different amplitudes of strain field in the soil

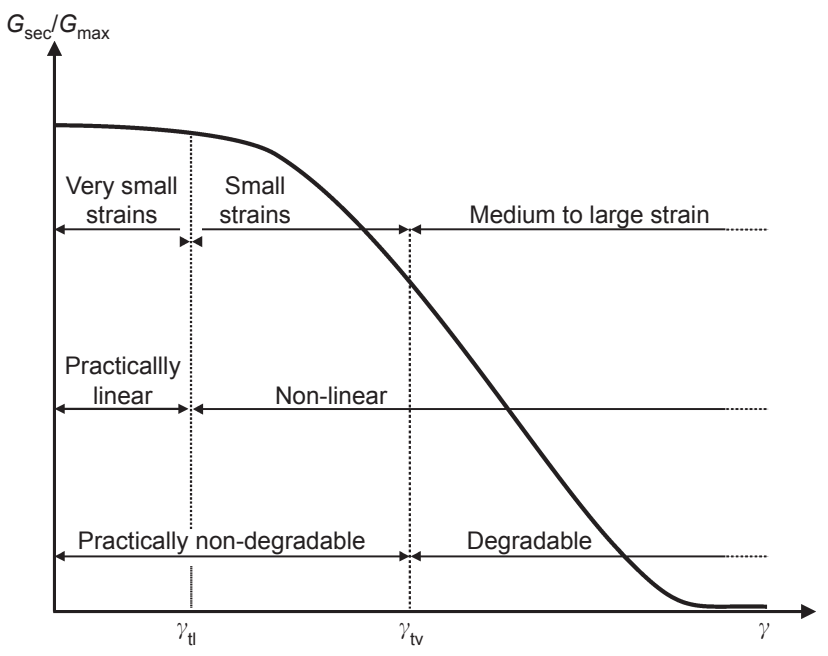

Figure 7. Secant shear modulus reduction curve for fully saturated cohesive soils cyclically sheared in undrained condition (after Vucetic, 1994)

used for designing the experiments, the model stiffness degradation (the drop in system frequency) will be slower than the prototype. This must be considered when upscaling the tests to predict the prototype consequences.

(b) The 'rate of loading parameter' $\left(k_{\mathrm{h}} / f_{\mathrm{f}} D\right)$ and 'system dynamics' $\left(f_{\mathrm{f}} / f_{\mathrm{n}}\right)$ cannot be simultaneously satisfied with the same pore fluid in model and prototype. It is obvious that $k_{\mathrm{h}}$ (coefficient of horizontal permeability) together with the diameter of the pile $(D)$ takes into account the drainage condition and the type of soil. Modelling both the non-dimensional groups together can be conveniently accommodated through the use of a different pore fluid

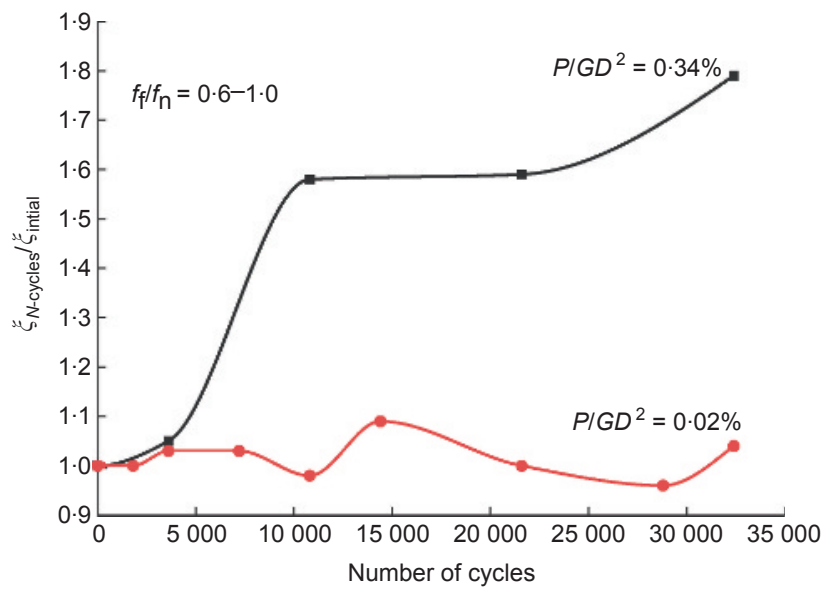

Figure 8. Change in damping with the number of cycles for different amplitudes of strain field in the soil 
International Journal of Physical Modelling in Geotechnics Volume 11 Issue 2
Similitude relationships for physical modelling of monopilesupported offshore wind turbines

Bhattacharya, Lombardi and Muir Wood

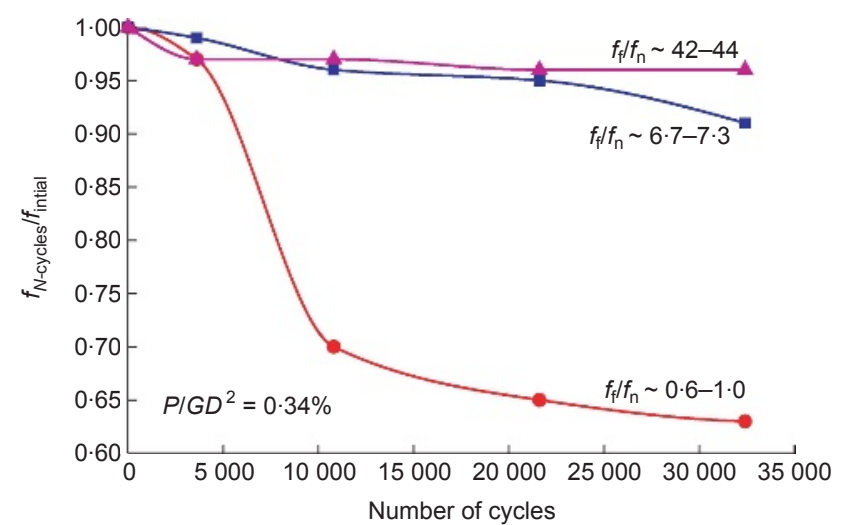

Figure 9. Change in frequency with the number of cycles for different ratio between forcing and natural frequencies

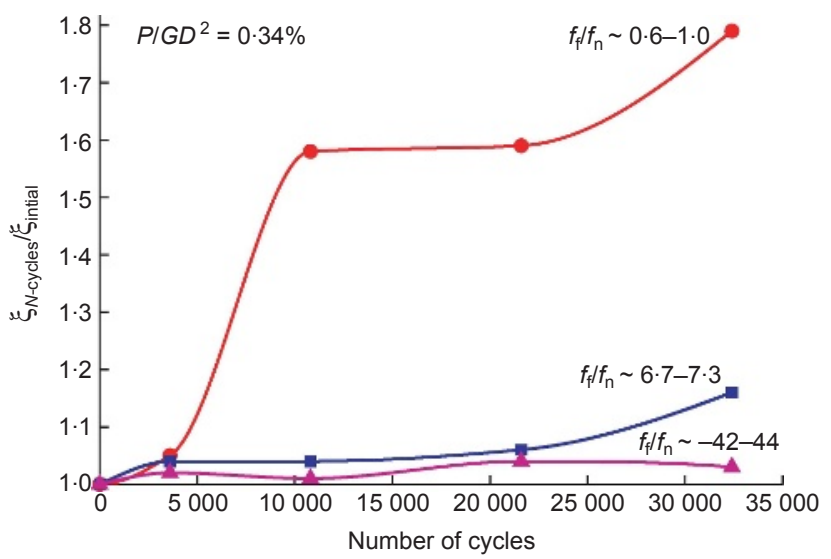

Figure 10. Change in damping with the number of cycles for different ratio between forcing and natural frequencies

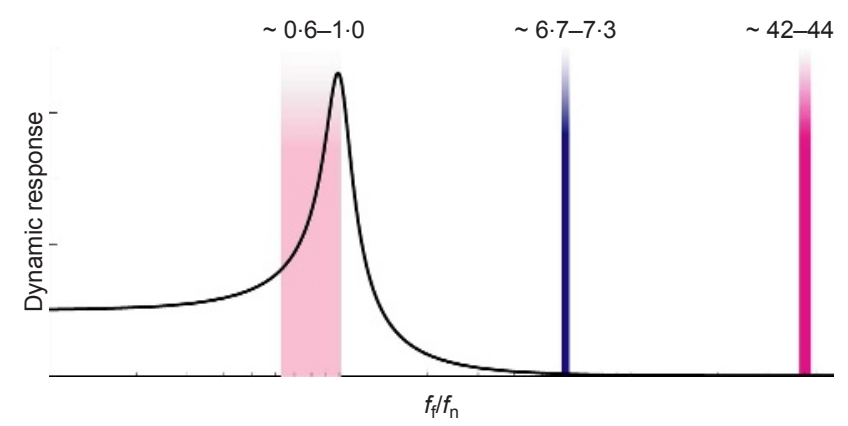

Figure 11. Deformation response for different ratios of forcingnatural frequency such as silicone oil or methyl cellulose solution for the model tests.

(c) It may be noted that soil strength $\left(S_{\mathrm{u}}\right)$ is not accounted for in any dimensionless group. This is because the focus of the current paper is on serviceability limit state, which requires stiffness of the soil $(G)$ at its core to carry out any calculations.

(d) Table 2 also shows that the stresses and the strains in the model pile are much lower than in the prototype. In particular, the strains in the model pile are one order of magnitude less than the prototype. In practice, monopiles are rigid and are designed to remain elastic in the design life. Therefore this low strain in the model piles would not affect the test results and the conclusions reached in the paper. However, if a thin-walled flexible pile is to be modelled then the material non-linearity of the pile has to be considered and then the dimensionless group given by Equation 14 has to be satisfied. On the other hand, the stresses in the model pile are two orders of magnitude lower than the prototype. This would ensure minimum reduction of fatigue life of the pile and the test results are unaffected by the fatigue phenomenon. Also, if the fatigue of the monopile is to be modelled, Equation 17 needs to be satisfied.

\section{Conclusions}

The paper shows that small-scale experimental studies can be carried out to study complex dynamic soil-structure interaction problems where there is no prior information. The longterm performance of offshore wind turbines has been studied because there is a real concern regarding the effect on performance of changes in the foundation stiffness.

Mechanics-based non-dimensional groups have been derived in order to study the various aspects of this problem and their validity has been verified using physical modelling. Under certain loading conditions, the natural frequency of the system decreases as a result of the effects of cyclic loading. These critical conditions relate to: (a) the strain level in the soil; and (b) the relative position of the system frequency in comparison to the forcing frequency.

The non-dimensional group representing the strain level in the soil is given by $\left(P / G D^{2}\right)$, which indicates that strain level in the soil adjacent to the pile decreases with square of the diameter. These results therefore justify the use of large-diameter monopiles as foundations for modern offshore wind turbines. Presently the majority of UK offshore turbines are built with steel monopile foundations, but for the new projects, which are at a greater distance from shore in much deeper water, and with far larger turbines, monopiles may become uneconomical owing to the large size required and the complexity of installation. 
Similitude relationships for physical modelling of monopilesupported offshore wind turbines

Bhattacharya, Lombardi and Muir Wood

\section{REFERENCES}

Adhikari S and Bhattacharya S (2010) Dynamic analysis of wind turbine towers on flexible foundations. Shock and Vibration, doi: 10.3233/SAV-2010-0615.

Adhikari S and Bhattacharya S (2011) Vibrations of windturbines considering soil-structure interaction. Wind and Structures 14(2): 85-112.

Cox J and Jones C (2010) Long-term Performance of Suction Caisson Supported Offshore Wind Turbines. Master's thesis, University of Bristol, UK.

DNV (Det Norske Veritas) (2002) Guidelines for Design of Wind Turbines, 2nd edn. DNV, London, UK.

DNV (2007) DNV-OS-J101: Offshore Standard: Design of Offshore Wind Turbine Structures. DNV, London, UK.

lai S (1989) Similitude for shaking table test on soil-structurefluid model in $1 \mathrm{~g}$ gravitational field. Soils and Foundations 29(1): 105-118.

Klar A (2008) Upper bound for cylinder movement using 'elastic' fields and its possible application to pile deformation analysis. International Journal of Geomechanics, ASCE 8(2): 162-167.

Kuhn M (2002) Offshore wind farms. In Wind Power Plants: Fundamentals, Design, Construction and Operation (Gasch $\mathrm{R}$ and Twele $\mathbf{J}$ (eds)). Solarpraxis AG, Berlin, Germany, pp. 365-384.

Leblanc C, Byrne BW and Houlsby GT (2010) Response of stiff piles to random two-way lateral loading. Géotechnique 60(9): 715-721.

Li Z, Haigh SK and Bolton MD (2010) The response of pile groups under cyclic lateral loads. International Journal of Physical Modelling in Geotechnics 10(2): 47-57.

Lombardi D (2010) Dynamics of Offshore Wind Turbines. MSc thesis, University of Bristol, UK.

Muir Wood D, Crewe AJ and Taylor CA (2002) Shaking table testing of geotechnical models. International Journal of Physical Modelling in Geotechnics 2(1): 1-13.

Seed HB and Idriss IM (1971) Simplified procedure for evaluating soil liquefaction potential. Journal of the Soil Mechanics and Foundations Division, ASCE 97(9): 12491273.

Vucetic M (1994) Cyclic threshold shear strains in soils. Journal of Geotechnical Engineering, ASCE 120(12): 2208-2228.

Wichtmann T, Niemunis A and Triantafyllidis T (2007) Strain accumulation in sand due to cyclic loading: drained cyclic tests with triaxial extensions. Soil Dynamics and Earthquake Engineering 27(1): 42-48.

Wroth CP, Randolph MF, Houlsby GT and Fahey M (1979) $A$ Review of the Engineering Properties of Soils with Particular Reference to the Shear Modulus. University of Cambridge, UK, Report CUED/D-SOILS TR75.

Zaaijer MB (2006) Foundation modelling to assess dynamic behaviour of offshore wind turbines. Applied Ocean Research 28(1): 45-57.

\section{WHAT DO YOU THINK?}

To discuss this paper, please email up to 500 words to the editor at journals@ice.org.uk. Your contribution will be forwarded to the author(s) for a reply and, if considered appropriate by the editorial panel, will be published as discussion in a future issue of the journal.

International Journal of Physical Modelling in Geotechnics relies entirely on contributions sent in by civil engineering professionals, academics and students. Papers should be 2000-5000 words long (briefing papers should be 10002000 words long), with adequate illustrations and references. You can submit your paper online via www.icevirtuallibrary.com/content/journals, where you will also find detailed author guidelines. 